\title{
POLÍTICAS PARA A EDUCAÇÃO INFANTIL NO ESTADO DE PERNAMBUCO: atendimento e autonomia municipal
}

\section{POLICIES FOR CHILDHOOD EDUCATION IN THE STATE OF PERNAMBUCO: service and municipal autonomy}

\author{
Maria Jaqueline Paes de Carvalho ${ }^{1}$ \\ Maria Eliete Santiago ${ }^{2}$

\begin{abstract}
"A humanidade deve à criança o melhor dos seus esforços" Declaração dos Direitos da Criança na Declaração das Nações Unidas, 1959.
\end{abstract}

\begin{abstract}
Resumo
Este artigo objetivou identificar a política de educação infantil do Estado de Pernambuco quanto ao atendimento e à situação de autonomia dos municípios, identificando a criação do Conselho Municipal de Educação (CME) e do Sistema Municipal de Ensino (SME). Tratou-se de uma pesquisa documental, e após a análise dos dados o estudo evidenciou que existe uma diferenciação quanto ao atendimento entre as regiões e as responsabilidades dos entes federados. Sobre a autonomia da gestão, 97\% dos municípios possuem CME, enquanto apenas $24,8 \%$ destes implementaram o SME. A Região Metropolitana se destacou quanto ao atendimento e autonomia pública na gestão.
\end{abstract}

Palavras-chave: Educação Infantil; Conselho Municipal de Educação; Sistema Municipal de Educação; Autonomia

\begin{abstract}
This article aimed to identify the infant education policy of the State of Pernambuco, regarding the attendance and the autonomy situation of the municipalities, identifying the creation of the Municipal Education Council (CME) and the Municipal Education System (SME). It was a documentary research, and, after analyzing the data, the study showed that there is a differentiation regarding the service between the regions and the responsibilities of the federated entities. Regarding management autonomy, 97\% of the municipalities have CME; while only $24.8 \%$ of these implemented the SME. The Metropolitan Region stood out in terms of service and public autonomy in the management.
\end{abstract}

Keywords: Early Childhood Education; Municipal Education Council; Municipal Education System; Autonomy

\footnotetext{
1 Doutora em Educação, Professora Adjunta da UFRPE, membro do GELPP (Grupo de Estudos e Pesquisas em Linguagens e Prática Pedagógica), e-mail: mariajaquelinepaescarvalho@gmail.com

2 Doutora em Educação, Professora Titular da UFPE/DAEPE; Professora do Programa de Pós-Graduação em Educação/UFPE, Coordenadora da Cátedra Paulo Freire/UFPE, e-mail: mesantiago@uol.com.br
} 


\section{dAEPEI}

\section{Introdução}

Ao traçar um caminho para entender as políticas voltadas para a educação infantil é salutar fazer referência ao conceito de política de forma geral. Política deriva do grego politeia, acepção voltada do termo policy, como um conjunto de medidas de que se servem os poderes públicos para a consecução dos seus objetivos (PORTO, 2006). Trata-se de um ordenamento das prioridades, das necessidades e dos interesses explicitados pela sociedade, com base nas forças presentes no exercício do poder.

Do ponto de vista educacional, destaca-se a natureza filosófica desta, que aponta em suas diretrizes o caráter ideológico e acadêmico, instaurado dentro de um tempo histórico determinado e em contextos indefinidos. Neste sentido, as políticas educacionais emergem da força da sociedade civil organizada, para que sejam postas em debate aberto com criticidade e criatividade, e ajam efetivamente na democratização, no fortalecimento e na legitimidade dos atores envolvidos no processo educacional (professores, crianças, pais e outros) (PORTO, 2006).

Política é uma ação do Estado materializada em uma questão que a sociedade colocou. Assim, as políticas educacionais integradas às políticas sociais englobam ações que os indivíduos e as instituições direcionem à dimensão prática. Houve um momento em que a sociedade pôs como uma questão importante a necessidade do atendimento das crianças de 0 a 6 anos, certamente guardando as devidas proporções entre as necessidades de cada época, inclusive do lugar em que a história da infância e da criança foram se constituindo.

Por muito tempo o Estado não garantiu o atendimento educacional da faixa etária de 0 a 5 anos, uma vez que via a criança como uma responsabilidade privada, da família (BARSOSA, 2009). No entanto, várias iniciativas da sociedade civil organizada foram sendo feitas pressionando o Estado a reconhecer a necessidade desse atendimento.

As disputas sociopolíticas vividas há mais de 100 anos pelos direitos da criança se intensificaram nas últimas quatro décadas, e mais recentemente, vem sendo reconhecido o caráter educacional dos serviços oferecidos às crianças de 0 a 5 anos. Vários fatores contribuíram para a expansão e valorização da educação infantil no Brasil e no mundo. A 


\section{REVISTA DE ADMINISTRAÇÃO EDUCACIONAL}

\section{ISSN -2359-1382}

\section{dAEPEI}

necessidade da mão de obra feminina no mercado de trabalho, necessidade essa proclamada com maior ênfase no século XIX, após a Revolução Industrial, para a reconstrução da Europa. Outro fator importante foi o avanço das pesquisas científicas sobre o desenvolvimento da criança, que contribuíram para o reconhecimento da sociedade sobre o papel da infância e os direitos das crianças nos primeiros anos de vida.

A valorização do atendimento às crianças pequenas apareceu com maior ou menor intensidade em períodos diferentes da história. Do ponto de vista legal, as primeiras constituições não se referiram à infância, especialmente as proclamadas antes de 1937. As de 1937 e 1946 se referiram à infância como amparo e cuidado, e, posteriormente, em 1967 e 1968, vislumbraram a assistência à criança. As instituições que prestavam atendimento à criança, geralmente filantrópicas ligadas a instituições não governamentais, eram vinculadas às secretarias de ação social e em sua maioria participavam de programas que visavam ao cuidado com uma concepção essencialmente assistencialista, em que se relacionava o direito a creche à mãe trabalhadora.

Contudo, a partir da promulgação, em 1988, da nova Constituição brasileira, evidenciou-se um marco na história da luta pela educação infantil como instância educativa. Seu texto assegura os direitos sociais à educação, à saúde, ao trabalho, à moradia, ao lazer, à segurança e à previdência social, proteção à maternidade e à infância, respaldados pelos artigos 206: “A educação é direito e dever do Estado e da família ...”; e 208: "Será efetivado mediante a garantia de .[..] atendimento em creches e pré-escola as crianças de 06 anos”. Percebe-se aí a perspectiva educacional do atendimento às crianças, uma vez que os artigos estão incluídos no capítulo da educação.

Entretanto, ao utilizar o termo atendimento, ao invés de acesso, no artigo 208, infere-se a não garantia do direito de forma universal. De certo que as atribuições estão explicitadas no documento, porém, não tão claras quanto ao financiamento e aplicabilidade em nível real, com vistas à garantia de uma prática educacional para as crianças. E, efetivamente, durante o século XX, o atendimento à infância não se concretizou (Kramer 1995).

A Carta Magna é um documento que mobilizou a sociedade civil organizada e os 
organismos governamentais para a garantia dos direitos da criança, ao mesmo tempo em que fez evoluir o estágio da consciência social sobre a criança como cidadã ativa socialmente. Dessa forma, garantiu-se o direito da criança a creches e pré-escolas e o dever do Estado em provê-las, desvinculando-se do requisito à mãe trabalhadora.

O histórico de mobilizações e de definições cumpre sua função histórica de fomentar o debate para o continuar dessa luta. Em 1990, a constituição federal se legitimou, quando foi sustentada na declaração mundial de educação para todos que a aprendizagem começa no nascimento (CORSINO, 2005). E, neste mesmo ano, no âmbito legislativo, foi elaborado e aprovado o ECA - Estatuto da Criança e do Adolescente. Embora este último reproduza os dispositivos constitucionais sobre a educação da criança de 0-6 anos, determina uma conquista, a criação de instrumentos que poderão influir decisivamente no atendimento aos direitos da criança (os conselhos de direitos das crianças e do adolescente. $\mathrm{O}$ artigo $5^{\circ}$ afirma que nenhuma criança ou adolescente será objeto de qualquer discriminação, violência, e prevê a punição por omissão ou ação aos seus direitos; no art. 53 o direito à educação deve ser respeitado pelos seus educadores.

Assim, os princípios, competências e atribuições do ECA reforçam e ampliam a Constituição Federal $^{3}$, no sentido de efetivar o direito do cidadão e o dever do Estado ao atendimento a essa etapa do desenvolvimento humano. Isso demanda a modificação de práticas históricas, garante financiamento e um intenso esforço da sociedade civil organizada (CURY, 1998).

Em 1993, o MEC (ministério da educação e cultura) / COEDI (coordenação de educação infantil) publicou documentos específicos para uma política nacional de educação infantil e de formação de seus profissionais (CORSINO; KRAMER; NUNES, 2005). Esses documentos objetivavam servir como diretrizes gerais para análise e discussão de propostas curriculares municipais para esse segmento de ensino, com vistas a ampliar o padrão de qualidade e a equidade no atendimento das crianças de 0 a 6 anos.

3 Essas leis aproximaram o entendimento de criança como sujeito de direitos, diferentemente de como se pensava nos anos 70, com uma política de educação compensatória, acreditando na criança pobre como sendo privada culturalmente. As ações e os programas pensados nessa época se fundamentavam na abordagem da privação cultural, que justificava e reforçava a discriminação de crianças das classes desfavorecidas (KRAMER, 1995). 


\section{REVISTA DE ADMINISTRAÇÃO EDUCACIONAL}

ISSN -2359-1382

\section{dAEPE| $\begin{aligned} & \text { Departamento de Administracaio } \\ & \text { Escolar e e Planejamento }\end{aligned}$}

Além disso, contribuíram para a defesa de uma infância com direitos sociais, ativa na construção dos seus conhecimentos, e a educação infantil como primeira etapa da educação básica. Os documentos, amplamente discutidos, colaboraram em dois projetos por uma nova Lei de Diretrizes e Bases da Educação Nacional (LDB) que circulavam no Congresso Nacional.

Nesse contexto, é relevante historiar como a criança foi citada nas outras versões da LDB. A de 1961 apresentava em seu texto referência à faixa etária de 0 a 7 anos e ditava que fossem ministradas em escolas maternais e jardins de infância ${ }^{4}$. A mesma lei sugere também a parceria das empresas com as escolas e/ou poderes públicos, para um atendimento em creches e pré-escolas para os filhos das operárias em serviço, além da exigência dos professores com curso normal completo. Em 1971, mantiveram-se esses ganhos reforçando a necessidade de as empresas organizarem e manterem instituições para crianças de 0 a 7 anos, modificando a nomenclatura de escola primária para escola de $1^{\circ}$ grau, e passaram para os sistemas de ensino o "zelo", "o cuidado" necessário ao atendimento a essas crianças (LUZ, 2006). Silva (2002) alerta para o fato de essas leis se referenciarem a crianças menores de 7 anos, por meio de palavras que expressam "estímulo, “cooperação", "zelo". Palavras bem distintas de "direito" e "responsabilidade".

A LDB, depois de sete anos de embates políticos, em 1996, projeto do deputado Darcy Ribeiro, instituiu a educação infantil como primeira etapa da educação básica, como matéria de natureza educacional. A partir dessa data, passou a ser papel do Estado, em instância municipal, assegurar a educação infantil para todas as crianças de 0 a 6 anos cujas famílias desejassem. Isto significa integrar aos sistemas municipais de educação as creches e pré-escolas da instância social. Desde então, esses espaços passaram a ser legalmente instituições educativas, coordenadas e orientadas pelas secretarias municipais de educação.

Porém essas mudanças não ocorreram simplesmente a partir de uma determinação legal, foi e está sendo um processo gradativo que exige reestruturações que vão desde a regulamentação dos conselhos municipais de educação até a captação de recursos físicos (equipamentos, materiais etc.), e financiamento para a qualificação e formação dos

4 Configurando-se a concepção ambientalista de criança que acredita que a aprendizagem acontece apenas por estímulos externos. 
profissionais que atuam nessas instituições (CORSINO et al, 2005). A integração acontece no sentido de respeitar diferenças, conhecer as instituições, as condições em que o atendimento é feito. Portanto, verificamos o quão importante se fazem as referências da LDB/96, que preceitua a educação infantil como primeira etapa da educação básica e institui o direito da criança menor de 6 anos à educação.

Assim sendo, este estudo objetivou identificar como a política de educação infantil do Estado de Pernambuco está acontecendo do ponto de vista da oferta da educação infantil, e a situação de autonomia dos municípios na gestão da educação infantil. Identificamos os municípios que criaram o seu Conselho Municipal de Educação (CME) e o Sistema Municipal de Ensino (SME) que tivessem proposta curricular sistematizada e publicada, além de apresentarem um quadro de professores efetivos habilitados, assim como a oferta para a educação infantil disponibilizada para crianças de 0 a 5 anos, em instituições próprias ${ }^{5}$.

\section{Metodologia}

Para responder a esse objetivo o estudo tomou como ponto de partida a busca em fontes documentais produzindo o levantamento dos dados. Estes foram obtidos em bancos de dados digitais federais, estaduais e municipais, a saber: Instituto Brasileiro de Geografia e Estatística - IBGE ${ }^{6}$ (Informações Básicas Municipais - 2014); Base de Dados do Estado de Pernambuco ${ }^{7}$ - BDE (matrícula inicial na educação infantil, por dependência administrativa, segundo o tipo de ensino - 2015); Instituto Nacional de Estudos e Pesquisas Educacionais Anísio Teixeira - INEP (Sinopse Estatística da Educação Básica - 2015); Sites das prefeituras municipais do Estado de Pernambuco (PE). Além da consulta a banco de dados digitais, recorremos a membros da UNCME- PE (União Nacional de Conselhos Municipais) e ao FEIPE (Fórum em Defesa da Educação Infantil de PE), pessoalmente

\footnotetext{
5 Chamamos de instituições próprias aquelas apropriadas para o ensino de crianças de 0 a 3 anos (creches) e crianças de 4 e 5 anos (pré-escolas) que apresentam espaços adequados a essa etapa da educação básica e são geridas e financiadas pelo poder público municipal.

6 IBGE- https://cidades.ibge.gov.br/ acessado em 13 de janeiro de 2017.

7 Base de Dados de PE - Anuário Estatístico de Pernambuco IBGE, baseado no Método de Tendências, para atender a requisitos de dados do Tribunal de Contas da União. http://www.bde.pe.gov.br/estruturacaogeral/conteudo_site2.aspx acessado em 13 de janeiro de 2017.
} 


\section{dAEPEI}

e/ou por meio de telefonemas e e-mails, com vistas a complementar e atualizar as informações.

Os dados sobre os CME foram localizados no site do IBGE (Perfil dos Municípios Brasileiros - Conselho Municipal de Educação), ao passo que para as informações sobre em quais cidades foram implantados o Sistemas Municipais de Educação (SME) o acesso ocorreu através de ligações e e-mail para a UNCME e secretarias de educação, e ao mesmo tempo, buscamos informações pessoalmente junto a funcionários, além de consultar colegas professores e conselheiros do FEIPE, os quais complementaram e atualizaram as informações. Segundo Silva et al (2009), o trabalho com fontes documentais suscita obstáculos (documentos incompletos, parciais, imprecisos), e o pesquisador deve saber avaliar a credibilidade e representatividade das fontes e assim compor suas informações com o que estiver disponível, uma vez que podem ser precisas para nos esclarecer sobre uma determinada realidade.

O levantamento produziu os dados relativos à existência, ou não, de SME e de CME. No caso de existência do CME, buscamos conhecer suas características: ano de criação, confirmação de paridade, quantidade de reuniões anuais e sua função educacional ${ }^{8}$.

Em Pernambuco, a quase totalidade dos municípios (180) apresentaram CME, a maioria deles criada nas décadas de 1990 e 2000 (149), em maior parte paritários (173), e apresentaram regularidade de reuniões, em média a cada dois meses. Por fim, quanto às suas funções: normativos, consultivos, fiscalizadores e deliberativos. Quanto à construção do Sistema Municipal de Ensino (SME), 46 (24,8\%) realizaram sua implementação.

$\mathrm{Na}$ organização dos dados foram elaborados dois mapeamentos: um relativo ao atendimento da educação infantil quanto à oferta de matrículas, por dependência administrativa e tipo de ensino (creche ou pré-escola) em Pernambuco, e outro que tratou

8 Essas informações foram sistematizadas em um quadro denominado: Municípios de Pernambuco que apresentam Conselho Municipal com Funções e Sistema Municipal de Educação, de acordo com a divisão geopolítica estadual. Em apêndice, encontrado em CARVALHO, Maria Jaqueline Paes de. Currículo e prática pedagógica na educação infantil. 2019. Tese (Doutorado em Educação) - Universidade Federal de Pernambuco, Recife, 2019. Disponível em: https://repositorio.ufpe.br/handle/123456789/35745 


\section{REVISTA DE ADMINISTRAÇÃO EDUCACIONAL}

\section{ISSN -2359-1382}

\section{dAEPEI}

das condições de autonomia desses municípios quanto ao investimento na organização da gestão pública, com a criação dos CME e implementação do sistema próprio de educação para o município, suas funções e atribuições.

\section{Atendimento da educação infantil}

Segundo dados do Censo Demográfico/2010 IBGE ${ }^{9}$, em Pernambuco existiam, em 2010, 820.479 crianças de 0 a 5 anos, das quais 345.771 frequentavam creche ou préescola $^{10}$. Esse dado, por si só, já revela o elevado déficit no atendimento às demandas educacionais por parte do Estado a essa etapa da educação infantil, uma vez que esse atendimento corresponde a 42\% do total. Portanto, em 2010 permaneciam sem atendimento 496.634 crianças de 0 a 5 anos.

Dados localizados junto à Base de Dados do Estado de Pernambuco (BDE, 2015), mostram o atendimento conforme o Quadro $\mathrm{n}^{\circ} 1$ a seguir:

Quadro 1- MATRÍCULA INICIAL NA EDUCAÇÃO INFANTIL, POR DEPENDÊNCIA

$\begin{array}{llllll} & \text { Estadual } & \text { Federal } & \text { Municipal } & \text { Privada } & \text { Total } \\ \text { CRECHE } & 368 & - & 46.220 & 46.452 & 93.040 \\ \text { PRÉ-ESCOLA } & 1.863 & - & 139.131 & 89.322 & 230.316 \\ \text { TOTAL } & 2.231 & - & 185.351 & 135.774 & 323.653\end{array}$

ADMINISTRATIVA, SEGUNDO O TIPO DE ENSINO EM PERNAMBUCO

FONTE: BDE - Base de Dados do Estado de Pernambuco - 2015 (Dados extraídos do Censo Escolar do Instituto Nacional de Estudos e Pesquisas Educacionais Anísio Teixeira).

Segundo a BDE, em 2015, 323.653 crianças encontravam-se matriculadas em alguma instituição de atendimento à primeira infância. Dados apresentados no Quadro 01 revelam que no ano de 2015, um total de 2.231 matrículas foram efetivadas em instituições estaduais, enquanto os municípios foram responsáveis pelo atendimento de 185.351 crianças, e a rede privada por 135.774 .

9

http://www.ibge.gov.br/home/estatistica/populacao/censo2010/caracteristicas_da_populacao/caracte risticas_da_populacao_tab_uf_zip_ods.shtm

10 Fonte: BRASIL. IBGE. Censo Demográfico 2010. Tabela 3.13.1.1. 
Percebemos que a matrícula inicial na educação infantil ocorre em maior número em instituições do poder público municipal, expressando o que diz a legislação educacional sobre sua responsabilidade com essa etapa da educação básica. Em contrapartida, nota-se que o atendimento pela instância estadual seguiu diminuindo, uma vez que desde a promulgação da Constituição Federal de $1988^{11}$ a educação infantil foi sendo pouco a pouco municipalizada. Observamos, ainda, uma forte participação das instituições privadas no atendimento à educação infantil, sobretudo no que se refere àquele que se faz por meio de creches, pois, segundo dados da BDE (2015), a participação da esfera privada (46.452) chega a ser praticamente igual àquela que se mostra na esfera pública (46.588).

Ao lançarmos o olhar sobre os dados referentes à matrícula inicial na educação infantil (creche e pré-escola) no Estado de Pernambuco ${ }^{12}$, chegamos a informações sobre a oferta a esse segmento e sua distribuição entre as regiões de desenvolvimento, conforme Quadro 2.

Quadro 2- DISTRIBUIÇÃO DE MATRÍCULA INICIAL NA EDUCAÇÃO INFANTIL (CRECHE E PRÉESCOLA) DE ACORDO COM A DIVISÃO GEOPOLÍTICA ESTADUAL/2015

$\begin{array}{lllll}\text { Regiões de desenvolvimento } & \text { Rede estadual } & \text { Rede municipal } & \text { Rede privada } & \text { Total } \\ \text { METROPOLITANA } & 324 & 42.248 & 65.100 & 107.672 \\ \text { AGRESTE CENTRAL } & 318 & 24.708 & 14.346 & 39.372 \\ \text { AGRESTE MERIDIONAL } & 298 & 19.321 & 5.837 & 25.456 \\ \text { AGRESTE SETENTRIONAL } & - & 13.621 & 6.541 & 20.162 \\ \text { MATA NORTE } & - & 13.831 & 10.082 & 23.913 \\ \text { MATA SUL } & - & 17.994 & 11.803 & 29.797 \\ \text { SERTÃO CENTRAL } & - & 6.001 & 1.404 & 7.405 \\ \text { SERTÃO DE ITAPARICA } & 905 & 5.914 & 718 & 7.537 \\ \text { SERTÃO DO ARAPIPE } & - & 10.996 & 1.912 & 12.908 \\ \text { SERTÃO DO MOXOTÓ } & 243 & 7.067 & 2.161 & 9.471 \\ \text { SERTÃO DO PAJEÚ } & - & 10.985 & 2.077 & 13.062\end{array}$

11 Art. 211. A União, os Estados, o Distrito Federal e os Municípios organizarão em regime de colaboração seus sistemas de ensino. § 1o A União organizará o sistema federal de ensino dos territórios, financiará as instituições de ensino federais públicas e exercerá, em matéria educacional, função redistributiva e supletiva, de forma a garantir equalização de oportunidades educacionais e padrão mínimo de qualidade do ensino mediante assistência técnica e financeira aos Estados, ao Distrito Federal e aos Municípios. § 2o Os Municípios atuarão prioritariamente no ensino fundamental e na educação infantil. § 3o Os Estados e o Distrito Federal atuarão prioritariamente no ensino fundamental e médio.

12 Obtidos junto à Sinopse Estatística da Educação Básica, 2015, produzida pelo INEP. 


\section{REVISTA DE ADMINISTRAÇÃO EDUCACIONAL}

\section{ISSN -2359-1382}

dAEPEI
SERTÃO
DO
SÃO 110
11.505
11.908
23.523

FRANCISCO

FONTE: Elaboração própria, a partir dos dados do INEP/ 2015

O Quadro 02 revela a distribuição da matrícula em doze (12) regiões, de acordo com a divisão geopolítica do Estado de Pernambuco e por tutela administrativa (pública estadual, pública municipal e privada).

A educação infantil, na rede estadual, está presente em seis das doze regiões (Metropolitana, Agreste Central, Agreste Meridional, Sertão de Itaparica, Sertão do Moxotó e Sertão do São Francisco), enquanto a rede pública municipal e privada têm oferta em todas as regiões. Há um destaque para a Região Metropolitana do Estado (RM), que apresenta a maior concentração de matrículas (107.672), e longe da segunda, a Agreste Central com 39.372. Observa-se também, na Região Metropolitana (RM), o alto número de escolas privadas quando comparadas às públicas. Fato que se destaca, uma vez que a lei determina ao poder público municipal a responsabilidade desse atendimento, como dito anteriormente. E, em decorrência dessa legislação, as instituições públicas sob a responsabilidade do Estado apresentam um quadro reduzido de vagas (e com tendência a diminuição) em creches e pré-escolas.

Outro aspecto a destacar nesse quadro diz respeito à diferença entre as regiões. Os sertões Central, Itaparica, Araripe, Moxotó, Pajeú, são as regiões com menor investimento em creches e escolas, mesmo na esfera privada. Diferem um pouco o Sertão do São Francisco, por se tratar de uma região cuja economia se baseia na pecuária e no plantio de culturas de subsistência. Tem uma grande cidade, Petrolina, que apresenta um dos maiores Índices de Desenvolvimento Humano - IDHM ${ }^{13}$ do Estado, além de apresentar o maior polo de produção de frutas de Pernambuco, destinadas à exportação. Inferimos que esses dados podem influenciar a ampliação por parte do atendimento à educação infantil.

Em síntese, existe uma diferenciação quanto ao atendimento à educação infantil, tanto nas responsabilidades dos entes federados, por parte das esferas públicas e privadas, quanto na regionalização, uma vez que há uma maior concentração na RM.

13 Ocupa o $6^{\circ}$ lugar no ranking com os índices de IDHM 0.697; IDHM Renda 0.695; IDHM Longevidade 0.799; IDHM Educação 0.611. 


\section{A criação de CME e SME e a autonomia na educação infantil}

Para verificar a autonomia dos municípios em relação à política para o atendimento à educação infantil recorremos à identificação dos municípios que criaram o Conselho Municipal de Educação (CME), e o Sistema Municipal de Ensino (SME). Para tanto utilizamos informações do IBGE (Perfil dos Municípios Brasileiros - Conselho Municipal de Educação, 2014).

Importante destacar o sentido de autonomia que ora tratamos, aquela voltada à participação social e política nas decisões, enfrentando os conflitos inerentes às dimensões individuais e coletivas que se expressam na distribuição do poder. Entendemos que, do ponto de vista administrativo, a autonomia exige uma mudança nas relações sociais (MOTA, 2001). Nessas relações os indivíduos vão construindo sua autonomia e contribuindo para a autonomia política e administrativa em prol da coletividade, pois a autonomia individual se desenvolve quando encontra um espaço antes habitado pela dependência ao outro, por conseguinte constitui sua liberdade. Por esse motivo, entendemos que a participação social é uma prática de liberdade, envolve condicionantes históricos, culturais, econômicos que atuam nas relações individuais e coletivas (FREIRE, 1996). Assim os conselhos são órgãos em que a participação administrativa se baseia na formação de comissões eleitas por tempo determinado, e com essa característica pode apresentar formas avançadas de participação e, em alguns casos, comissões de representação (MARTINS, 2002). E, "nessa perspectiva, os movimentos autônomos e/ou participativos constituem o amplo cenário político e social que alimentam o antagonismo que fundamenta as relações sociais" (ibidem, p. 210).

Assim sendo, os Conselhos, em uma gestão pública, proporcionam uma maior interação entre Estado e sociedade civil e se tornam um mediador de qualidade, instrumento de expressão, representação e participação da população (GOHN, 2011), apresentando uma nova concepção de cidadania na qual todos os sujeitos sociais possuem o legítimo direito de deliberar sobre a gestão pública (GUIMARÃES, 2012; GOHN, 2011). São formadas por representantes do Estado e da sociedade civil, com poderes consultivos 


\section{REVISTA DE ADMINISTRAÇÃO EDUCACIONAL}

ISSN -2359-1382

\section{dAEPE| $\begin{aligned} & \text { Departamento de Administracaio } \\ & \text { Escolar e e Planejamento }\end{aligned}$}

e/ou deliberativos, reúnem elementos da democracia representativa e da democracia direta.

Segundo Avritzer (2000, p. 18), são “instituições híbridas”. São órgãos que atuam na prestação de serviços públicos (saúde, educação, transportes etc.). No caso da educação nos municípios, há quatro tipos de conselhos: Conselho da Alimentação Escolar (CAE), Conselho Escolar (CE), Conselho Municipal de Educação (CME), e, desde 1996, o Conselho de Acompanhamento e Controle Social do Fundef, o atual Fundeb (GUIMARÃES, 2012).

Neste estudo, o foco vai ao encontro de informações que dizem respeito à criação do CME de Pernambuco. Segundo Gonh (2011), os CME são órgãos que apesar de apresentarem alguns pontos de fragilidade em relação à sua organização e funcionamento (nomeação do chefe do executivo para presidência do conselho; necessidade de superar limites técnico-burocráticos), ainda representam um dos canais de participação que se constituem espaços de decisão ocupados pela sociedade, referendando a autonomia dos municípios. Daí sua importância na formulação e no controle da educação infantil.

Assim, buscou-se nos documentos do IBGE - 2014, informações sobre os CME, como eles foram criados e como estão organizados. De acordo com esse levantamento, podemos observar que no Estado de Pernambuco, dos 185 municípios, 180 possuem CME. O mais antigo conselho implementado data de 1970, em Caruaru, seguido de Recife, em 1971. Na década de 1980 apenas um município o implementou. A grande maioria (82\%) foi sendo criada na década de 1990 e 2000. Com destaque para a gestão do então governador Miguel Arraes e da secretária de Educação Silke Weber ${ }^{14}$ (1995-1999), em que foram criados CME em 71 munícipios.

Vale salientar que esse governo acreditava na concepção de gestão participativa, investiu em projetos de construção de CME, com vistas a contribuir para a autonomia dos municípios, o que nos faz entender a razão desse grande número de municípios com CME criados em sua gestão. Isso demonstra que a participação popular só veio a aumentar a

14 Para maior aprofundamento sobre a gestão da Secretaria de Educação de PE na gestão de Miguel Arraes ver: GUEDES, Marília Gabriela de Menezes. Contribuições de Paulo Freire para as políticas e práticas curriculares nos sistemas de ensino. Tese de doutorado. Universidade Federal de Pernambuco - UFPE. Recife: PP.236, 2011. 
partir dos anos 1990, quando o princípio da gestão democrática orientou a criação de conselhos como instâncias participativas na representação e ampliação da esfera pública, ampliando o fortalecimento da sociedade civil na participação nas ações do Estado. Esse contexto corrobora os dados sobre a paridade dos CMEs no Estado de Pernambuco que atinge $96 \%$.

Com relação à sua função, os CME se caracterizam como normativos 57\% (103), consultivos $85 \%$ (153), fiscalizadores $74 \%$ (134), e deliberativos $86 \%$ (156) ${ }^{15}$. Podemos observar que a grande maioria dos conselhos apresenta de três a quatro atributos simultaneamente, com ênfase no aspecto deliberativo. Isso parece dizer que os conselhos foram criados com o objetivo maior de gerir a educação municipal e contribuir com o seu crescimento.

Em relação aos SME, trata-se da organização legal dos elementos que se articulam na efetiva concretização da autonomia do município, na área da educação. O SME é composto pelas instituições públicas municipais de educação básica; instituições privadas de educação infantil; Secretaria Municipal da Educação; Conselho Municipal de Educação (CME); Conselho Municipal do FUNDEF - o qual pode integrar o CME como câmara; conselho municipal da alimentação escolar. Cada sistema de ensino atua em função das necessidades e dos objetivos específicos de sua região, submetidos às diretrizes gerais da Educação Nacional - LDB Art. 18 (TOCANTINS, 2007).

Para conhecer a existência dos sistemas municipais de ensino do Estado de Pernambuco foi realizado um levantamento a partir de três fontes. As geradas pela UNCME - PE, aquelas buscadas pessoalmente, e outras originadas a partir dos sites das secretarias de educação.

15 Normativo - só é exercida quando existe o sistema de ensino próprio. Ele pode, assim, elaborar normas complementares às nacionais em relação às diretrizes para regimento escolar, determinar critérios para acolhimento de alunos sem escolaridade e interpretar a legislação e as normas educacionais. ConsultivoResponder a consultas sobre alvará, credenciamento e leis educacionais e suas aplicações, submetidas a ele por entidades da sociedade pública ou civil (Secretaria Municipal da Educação, escolas, universidades, sindicatos, câmara municipal, Ministério Público), cidadão ou grupo de cidadãos. Fiscalizador - promover sindicâncias, solicitar esclarecimento dos responsáveis ao constatar irregularidades e denunciá-las aos órgãos competentes. Deliberativo - essa atribuição deverá ser definida na lei que cria o conselho, que pode, por exemplo, aprovar regimentos e estatutos; autorizar cursos, séries ou ciclos; e deliberar sobre os currículos propostos pela secretaria (Secretaria Municipal de Educação, Ministério Público, Tribunal de Contas, Câmara dos Vereadores). 


\section{REVISTA DE ADMINISTRAÇÃO EDUCACIONAL}

\section{ISSN -2359-1382}

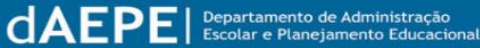

No que se refere a essa questão, dos 185 municípios de Pernambuco, 141 são subordinados ao Sistema Estadual de Educação. Destes, 46 organizaram seus SME distribuídos pelas regiões de desenvolvimento, de acordo com a divisão geopolítica do Estado (UNCME, 2013), como mostra o Quadro 03, a seguir.

Quadro 3- MUNICÍPIOS QUE APRESENTAM SME DE ACORDO COM A DIVISÃO GEOPOLÍTICA DO ESTADO DE PERNAMBUCO

$\begin{array}{lll}\text { REGIÕES DE } & \text { NÚMERO } & \text { NÚMERO DE } \\ \text { DESENVOLVIMENTO } & \text { DE MUNICÍPIOS } & \text { MUNICÍPIOS COM SME } \\ \text { Região Metropolitana } & 15 & 09 \\ \text { Agreste Central } & 26 & 05 \\ \text { Agreste Meridional } & 26 & 01 \\ \text { Mata Norte } & 19 & 02 \\ \text { Mata Sul } & 24 & 07 \\ \text { Sertão Central } & 08 & 03 \\ \text { Sertão Itaparica } & 07 & 02 \\ \text { Sertão do Araripe } & 10 & 05 \\ \text { Sertão do Moxotó } & 07 & 00 \\ \text { Sertão do Pajeú } & 17 & 08 \\ \text { Sertão do são Francisco } & 07 & 01 \\ \text { Total } & 185 & 46\end{array}$

FONTE: Elaboração própria a partir dos dados da UNCME, 2013

A Região Metropolitana do Estado $(\mathrm{RM})^{16}$ tem o maior atendimento à educação infantil e concentra o maior número de SME implementados. Dos quinze munícipios, nove apresentam SME. Quanto às outras regiões, vemos algumas que nenhum dos seus municípios tem SME, a exemplo do Sertão do Moxotó.

Percebemos, assim, que a maioria dos municípios de Pernambuco mostrou-se, qualitativamente, menos autônomo na constituição e gerenciamento de suas ações pedagógicas e políticas administrativas, quando opta pela não implementação do eu sistema de ensino, acarretando a não adequação das estruturas legais às peculiaridades locais.

A legislação brasileira teceu orientações a partir de 1996, data da promulgação da

16 RM: também chamada de Grande Recife (GR), que possui o maior aglomerado urbano do Norte-

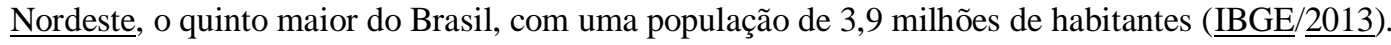




\section{REVISTA DE ADMINISTRAÇÃO EDUCACIONAL}

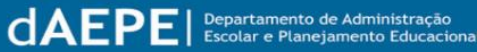

LDB, sobre a implementação dos sistemas de ensino e a integração da educação infantil. A lei estabelece, em seu artigo 89, das disposições transitórias, o prazo de três anos para que as creches e pré-escolas já existentes e as que vierem a ser criadas sejam integradas ao sistema de ensino, pois respondem às necessidades e direitos das crianças de 0 a 5 anos (BRASIL, 2000) ${ }^{17}$. A legislação também prevê a opção do município quanto a constituir sistema de ensino próprio ou integrar-se ao sistema de ensino estadual - essa integração há de ser realizada mediante entendimento entre os dois sistemas, em que fiquem claras as responsabilidades de cada um. A opção pela vinculação ao Sistema Estadual de Educação acarreta o caráter não normativo e não deliberativo do $\mathrm{CME}$, porque o município abre mão de parte de sua autonomia (TOCANTINS, 2007).

Salienta-se que a criação do SME se torna importante para o município, uma vez que guarda autonomia ao tomar suas decisões e fazer suas opções políticas sem ter que se submeter a outra instância. Passa a se tratar de uma organização legal e institucional, com um conjunto de elementos autônomos (órgãos e instituições, com seus respectivos profissionais, normas, planejamento, recursos financeiros e culturais) que interagem intencionalmente em prol da educação (TOCANTINS, 2007).

Com relação a este aspecto levantado, o estudo revelou que no Estado de Pernambuco poucos municípios aderiram à implementação do SME, e a região que se destacou quanto à autonomia pública foi a Região Metropolitana. Nela verificamos uma concentração (dos quinze munícipios, nove apresentam tal característica) de municípios com SME organizados.

\section{Considerações Finais}

O tratamento dado à educação infantil no Brasil vem legalmente alcançando avanços significativos na busca de garantir o direito ao atendimento das crianças em creches e pré-escolas. Sabe-se que ainda é necessário maior investimento para que de fato a meta $01^{18}$ do Plano Nacional de Educação seja efetivada. Realizamos este estudo com o

17 Diretrizes operacionais para a educação infantil- Despacho do Ministro, publicado no Diário Oficial da União de 6/7/2000.

18 Universalizar, até 2016, a educação infantil na pré-escola para as crianças de 4 (quatro) a 5 (cinco) anos de idade e ampliar a oferta de educação infantil em creches de forma a atender, no mínimo, 50\% (cinquenta 


\section{REVISTA DE ADMINISTRAÇÃO EDUCACIONAL}

\section{ISSN -2359-1382}

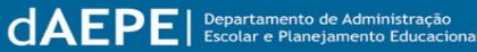

propósito de identificar como o Estado de Pernambuco está gerindo as políticas públicas relacionadas à gestão e ao atendimento da educação infantil.

Percebemos que, quanto ao direito ao atendimento, existe uma diferenciação de acordo com as regiões políticas administrativas, e a responsabilidade pelo atendimento, se estadual, municipal ou privada. A rede pública estadual vem diminuindo o atendimento desde a LDB (1996), que instituiu a responsabilidade da educação infantil ao poder público municipal. De fato isso sucede, os municípios vêm assumindo tal responsabilidade, e hoje são os entes federados que atendem ao maior número de crianças de 0 a 5 anos. A rede privada vem em segundo lugar no atendimento com uma pequena diferença quantitativa.

Em relação à autonomia dos municípios na gestão dessa etapa de ensino, identificamos os municípios que criaram o Conselho Municipal de Educação (CME) e o Sistema Municipal de Ensino (SME). A análise dos dados mostrou que existe um bom quantitativo de municípios que têm $\mathrm{CME}$, mas ainda um percentual muito baixo quanto à implementação do SME. Dos 185 municípios de Pernambuco, 46 organizaram seus SME, os outros 141 são subordinados ao Sistema Estadual de Educação. Essa opção por se vincular ao Sistema Estadual de Educação nos chamou a atenção, pois a implementação do SME garante ao município tomar suas próprias decisões, fazer suas opções políticas, sem ter que se submeter a outra instância. Passa a ser uma organização legal e institucional, com um conjunto de elementos que geram maior autonomia para a gestão.

Por fim, outro dado importante verificado foi o destaque que teve a Região Metropolitana do Estado face às duas categorias analisadas.

Em posse desses dados, duas questões importantes surgem para ampliação da discussão: Por que tanto espaço social e político ocupa a rede privada de ensino ao atendimento de crianças de 0 a 5 anos no Estado de Pernambuco? Qual o investimento político que o Estado está viabilizando para que seus municípios implementem seus SME? Essas são temáticas que poderão ser levantadas em outros estudos sobre a relação entre população, oferta e atendimento na educação infantil e a valorização da autonomia da gestão educacional municipal.

por cento) das crianças de até 3 (três) anos até o final da vigência deste PNE (BRASIL, 2014 p 42 ). 


\section{Referências}

AVRITZER, Leonardo. Teoria democrática, esfera pública e participação local. In: Sociologias. Porto Alegre, IFCH-UFRGS, ano 1 n. 2, pp. 18-43, 2000.

BARBOSA, Maria Carmem S. et all. Práticas cotidianas na educação infantil - bases para reflexão sobre as orientações curriculares. Projeto de Cooperação Técnica MEC e UFRGS para construção de orientações curriculares para a educação infantil. Brasília: MEC/SEB/UFRG, 2009.

BRASIL. Senado Federal. Constituição da República Federativa do Brasil. Brasília: Centro Gráfico, 1988. 292 p.

1990.

. Senado. Estatuto da criança e do adolescente: lei nº 8.069/1990. Brasília, DF,

Lei $\mathbf{n}^{\circ}$ 9.394, de 20 de dezembro de 1996. Estabelece as Diretrizes e Bases da Educação Nacional. Brasília, DF, 1996.

CORSINO, Patrícia, NUNES Maria Fernanda e KRAMER, Sonia. Formação de profissionais da educação infantil: um desafio para as políticas municipais e educação face às exigências da LDB. In: SOUZA, D. Bello, e FARIA, Lia. Desafios da educação municipal . Rio de Janeiro, DP\&A, 2003, p. 278-304.

CORSINO, Patrícia (org.). Educação Infantil: cotidiano e políticas. Campinas, SP: Autores Associados, 2009.

CURY, Carlos Roberto Jamil. A educação básica como direito. Cadernos de Pesquisa, v. 38, n. 134, p. 293-303, maio/ago. 2008.

FREIRE, Paulo. Educação como prática da liberdade. Rio de Janeiro: Paz e Terra, 1981

GUIMARÃES, Carlos Sant'Anna. Participação sociopolítica e governança democrática: o papel dos conselhos municipais de educação na gestão e implementação da política educacional. 2012.

GOHN, Maria da Glória. Participação de representantes da sociedade civil na esfera pública na América Latina. Revista Política e sociedade. Volume $10-\mathrm{N}^{\circ} 18$ - abril de 2011. p 233.

KRAMER, Sonia. A política do pré-escolar no Brasil: a arte do disfarce. 5. ed. São Paulo: Cortez, 1995.

LUZ, Isa. Rodrigues da. Educação infantil: direito reconhecido ou esquecido? Linhas 


\section{REVISTA DE ADMINISTRAÇÃO EDUCACIONAL}

\section{ISSN -2359-1382}

\section{dAEPE|}

Críticas, Brasília, v. 12, nº. 22, p. 41-58, jan./jun. 2006

MARTINS, Ângela Maria. Autonomia e educação: a trajetória de um conceito. Cadernos de Pesquisa, n. 115, pp. 207-232, março/ 2002.

MOTTA, Fernando C. Prestes. Administração e participação: reflexões para a educação. Educação e Pesquisa, São Paulo, v.29, n.2, pp. 369-373, jul./dez. 2003.

PORTO, Zélia. Granja. Participação social e políticas de educação infantil no Brasil. Lugares de produção e circulação de discursos: 1970-2000. In: SOUZA, João Francisco. (Org.). E a pesquisa educacional brasileira. O Centro de Educação da UFPE no XIV Colóquio da AFIRSE. Recife: Ed. Bagaço, 2006, v.p. 127-148

SILVA, Jackson Ronie Sá; ALMEIDA, Cristóvão Domingos; GUINDANI, Joel Felipe. Revista Brasileira de História \& Ciências Sociais. Ano I - Número I - Julho de 2009

TOCANTINS. União dos Conselhos Municipais de Educação - UNCME/TO. Cartilha Pró-Conselho, Criação de CME- SME. Palmas, 2007. 